\title{
Students' perceptions about online teaching effectiveness: A bottom-up approach for identifying online instructors' roles
}

\author{
Pilar Gómez-Rey, Elena Barbera \\ Universitat Oberta de Catalunya, Barcelona
}

\author{
Francisco Fernández-Navarro \\ Universidad Loyola Andalucía, Sevilla
}

\begin{abstract}
The topic of online instructors' roles has been of interest to the educational community since the late twentieth century. In previous studies, the identification of online instructors' roles was done using a top-down (deductive) approach. This study applied a bottom-up (inductive) procedure to examine not only the roles of online instructors from a student perspective, but also how well these roles are implemented in practice. In the first stage, roles were defined using factor analysis on a sample of 925 students. A questionnaire was created after an extensive literature review and in-depth interviews with experts. The methodology detected six roles: pedagogical, course designer, social, life skills promoter, technical, and managerial. In the second stage, students' scores were projected over those factors to obtain the instructors' performance in each role (the significance of the results was assessed using non-parametric tests). Main findings included: (i) the emergence of a new role, the life skills promoter; (ii) online scenarios becoming more transparent and intuitive due to syllabus design; (iii) the consideration of more audio-visual resources by instructors in asynchronous learning environments; and (iv) the value of offering guidelines to students for collaborative activities to reduce the level of frustration with these activities.
\end{abstract}

\section{Introduction}

Preparing instructors for the twenty-first century requires a close analysis of what it means to teach and learn in increasingly knowledge-based, technology-rich, and digital classrooms. In the twentieth century, higher education focused on the transmission educational model, based on the transmission of facts from teacher to learner, however, the understanding of what constitutes quality in education is evolving. In the past, much of the emphasis in education was related to declarative knowledge. There is now a need to focus on other dimensions of learning, such as lifelong, social and relationship skills, cultural sensitivity to other life perspectives or ethnicities, and digital skills, among others (Pellegrino \& Hilton, 2013).

In this way, education should incorporate into its procedures, promoting the development of the previously mentioned skills. Therefore, the nature of teaching and its effectiveness must also adapt to this new reality. According to Gorsky \& Blau (2009), teaching effectiveness may be defined as "how an instructor can best direct, facilitate and support students toward certain academic ends, such as achievement and satisfaction” (p. 1). In the literature, there are numerous studies that evaluate teaching effectiveness using different data sources, for example student ratings, peer ratings, self-evaluation, or student interviews (Berk, 2005). In this study, we have considered students' ratings to evaluate teaching effectiveness, as students are at the core of the new learning paradigms (Schweisfurth, 2015). The main drawbacks of evaluating teaching effectiveness using students' perceptions are: (1) students are not subject matter experts and, therefore, are not in a position to make judgments about the currency or accuracy of the course; and (2) students' perceptions are sometimes influenced by their own motivations, attitudes, and needs (Fox \& Hackerman, 2003). Despite these drawbacks, different studies have confirmed the validity and reliability of assessing instructors using students' perceptions since the late twentieth century (Marsh, 1984; McKeachie, 1979).

This study investigates teaching effectiveness by analysing how well online instructors perform their roles and duties. Before summarising the main research works in the literature related to instructors' roles, it is important to define what is meant by role, competency, and output: three terms that are inherent in the topic of instructors' roles. According to Thach and Murphy (1995), a role is defined as "a major function which is performed by individuals in a specific field or profession"; a competency is defined as "an area of knowledge or skills which is critical to the production of key outputs"; and an output is defined as "a product, service, condition, and/or information which results from performing a 
specific role” (p. 58). We have constrained the scope of this study to focus on online instructors' roles and outputs, discarding the evaluation of instructors' competencies. We believe that if students were asked to rate these skills directly, the results would not be reliable.

\section{Literature review}

Since 1994, online instructor roles, competencies and outputs have been studied in distance education scenarios and online education environments (Abdulla, 2004; Berge, 1995; Bezuidenhout, 2015; Goodyear, Salmon, Spector, Steeples, \& Tickner, 2001; Goold, Coldwell, \& Craig, 2010; GonzálezSanmamed, Munoz-Carril, \& Sangra, 2014; Shaikh \& Khoja, 2014 Thach \& Murphy, 1995). For example, Thach and Murphy (1995) studied instructors' roles in distance education through qualitative analysis, using a Delphi study with experts on the field, and identified 11 online instructor roles: instructor, instructional designer, technology expert, technician, administrator, site facilitator, support staff, editor, librarian, evaluation specialist, and graphic designer. Goodyear et al. (2001) also investigated the topic and identified eight roles: content facilitator, technologist, designer, manager/administrator, process facilitator, adviser/counsellor, assessor, and researcher, using qualitative analysis based on experts' reports. Abdulla (2004) extended the research of Thach \& Murphy (1995) using students' perceptions and adopting Berge's role-based educational model (Berge, 1995). Abdulla (2004) concluded that there were significant differences among students' perceptions and experts' perceptions regarding the most important online instructor roles. Experts rated the social role as the most important one, whereas students considered that the most important role was the one related to content knowledge. On the other hand, both experts and students concurred that the managerial role should be included in the list of most important roles. More recently, the study by González-Sanmamed et al. (2014) determined online university instructors' levels of proficiency in their peripheral roles of social, evaluative, managerial, technological, counselling, personal, and research, again using a qualitative approach based on a sample of instructors from a Spanish university. González-Sanmamed et al. (2014) found that instructors stressed the importance of the peripheral roles for quality teaching and for that reason, they proposed that professional development programmes should include not only training on the central role (pedagogical) but also on the peripheral roles (social, managerial, etc.).

Although there have been numerous studies analysing this topic, we observed that there was no real consensus in the literature about the total number of online instructor roles. Two issues arose as impediments: (1) the number of instructor roles using a top-down (inductive) approach where the instructors' roles are estimated in a first stage using qualitative techniques and then the outputs associated to each role are defined; and (2) the instructors' roles vary depending on the context (e.g., primary, secondary, postsecondary), content (e.g., science, literature, history), and course goals (e.g., mastery of content, acquisition of skills, problem solving).

The main research questions of this study are:

1. What are the main roles of online instructors in the twenty-first century from students' points of view?

2. How are those roles being implemented according to students' perceptions?

The methodological approach was based on the combination of quantitative and qualitative techniques (mixed methods research), aiming to overcome the first limitation detected in the literature, which rely only on qualitative techniques. Factor analysis allowed us to cluster the set of indicators that defined effective instruction into the optimal number of instructors' roles. After identifying the instructors' roles, students' scores were projected over those roles to obtain the performance of each of the roles detected. Non-parametric statistical tests were used to measure how online instructors' roles in the twenty-first century are being implemented in practice. Template analysis was also implemented to support the empirical results with qualitative data. 


\section{Method}

\section{Procedures}

Data was collected through an online questionnaire administered to students from the Universitat Oberta de Catalunya (UOC) in Spain. The questionnaire, which was originally written in English and then translated into the university's official language(s) (Catalan and Spanish), was given to the students by their teachers at the end of the semester. The study focused on instructors who were teaching in the second semester of 2015 in subjects related to technical and social science disciplines. In this regard, the teacher selection was purposive. The questionnaire, which was built using the Google Forms tool, was available for 4 weeks. It was designed after an extensive literature review and in-depth interviews with experts on the topic (teaching tasks/roles in online environments), and incorporated students' perceptions. In this way, the list of items (instructors' outputs) was created using instructors' and students' perceptions. Regarding instructors' perceptions, a panel of experts evaluated the suitability of the items selected (Sekaran \& Bougie, 2010). Specifically, the list of items was distributed to six experts in the field that assessed the content, layout, and adequacy of the items that defined the teaching tasks of online instructors. Each of these experts had more than 15 years of experience in online learning scenarios and had previously researched the topic of online instructors' roles. After several research interviews, all the experts confirmed the validity of the final instrument. Regarding students' perceptions, a pilot study with 30 students allowed us to test the reliability of the proposed instrument. The above sources led to the development of the final instrument, which was composed of 69 items that define the teaching duties and responsibilities of online instructors (scored on a 5-point Likert scale). At the end of the questionnaire, we also included an open-ended question to assess the extent to which empirical results were aligned with qualitative data. The questionnaire also comprised seven demographic items to characterise the sample (Appendix A).

\section{Participants}

The participants in the study were 925 undergraduate students (6.66\% response rate) taking psychology (8.09\% response rate), business administration (6.38\% response rate), and computer science (3.42\% response rate) courses at the UOC. The majority of the participants (851) were aged between 18 and 48 , and the remaining 74 participants were all over 49 years old. Most of the participants were Spanish (95.90\%) and lived in Spain (95.40\%). There were 361 (39\%) males and 564 (61\%) females. While a small percentage of participants (12.60\%) were students with no family or work commitments, $87.40 \%$ needed to balance their studies with family and work commitments. Finally, $42.40 \%$ of students were inexperienced in an online environment, whereas $57.60 \%$ were previously experienced in this type of environment.

\section{Data analysis}

The methodology was based on a combination of qualitative and quantitative techniques. Quantitative analysis was performed through factor analysis and hypothesis testing, whereas qualitative analysis was conducted through template analysis.

\section{Quantitative analysis}

In quantitative terms, the computation of the teaching effectiveness was performed in a 2-stage algorithmic procedure. In the first stage, factor analysis was implemented to define the instructors' roles. The sample of 925 students was divided in two datasets (using stratified random sampling based on two demographic variables: degree and gender) to ensure the generalisability of the findings. The first dataset, consisting of 613 students, was used to assess the factor structure of the scale items through exploratory factor analysis (EFA). The EFA procedure was performed with promax rotation to allow the factors to correlate. Questions that did not correlate significantly to any factor were dropped. A factor loading cutoff of 0.40 (McCrae \& Terracciano, 2005) was used. Variables that grouped together without any logical meaning were also dropped. The second dataset, consisting of 312 students, was used to test the factor structure of the scale obtained from the EFA through confirmatory factor analysis (CFA). Next, the scores corresponding to each role were obtained by weighting the outputs obtained in each question defining the 
role by its corresponding factor loading. Finally, statistical tests were applied to ascertain the statistical significance of the differences observed between the mean scores of the different roles provided by the students.

\section{Qualitative analysis}

In this research study, template analysis was implemented to thematically organise qualitative data provided by students (305 students' comments) in the last question of the questionnaire (an open-ended question in which students are allowed to express their opinions about their learning experience) (Brooks, McCluskey, Turley, \& King, 2015). Two of the authors (coders) performed the coding task. The initial template was inspired by the input-process-output educational framework (Gómez-Rey, Barbera, \& Fernández-Navarro, 2016a; Gómez-Rey, Barbera, \& Fernández-Navarro, 2016b). After several iterations, the coders decided to eliminate the input construct from the code template (along with its associated codes) as those elements are implicit to the students and they cannot be modified during the learning process (Figure 1).

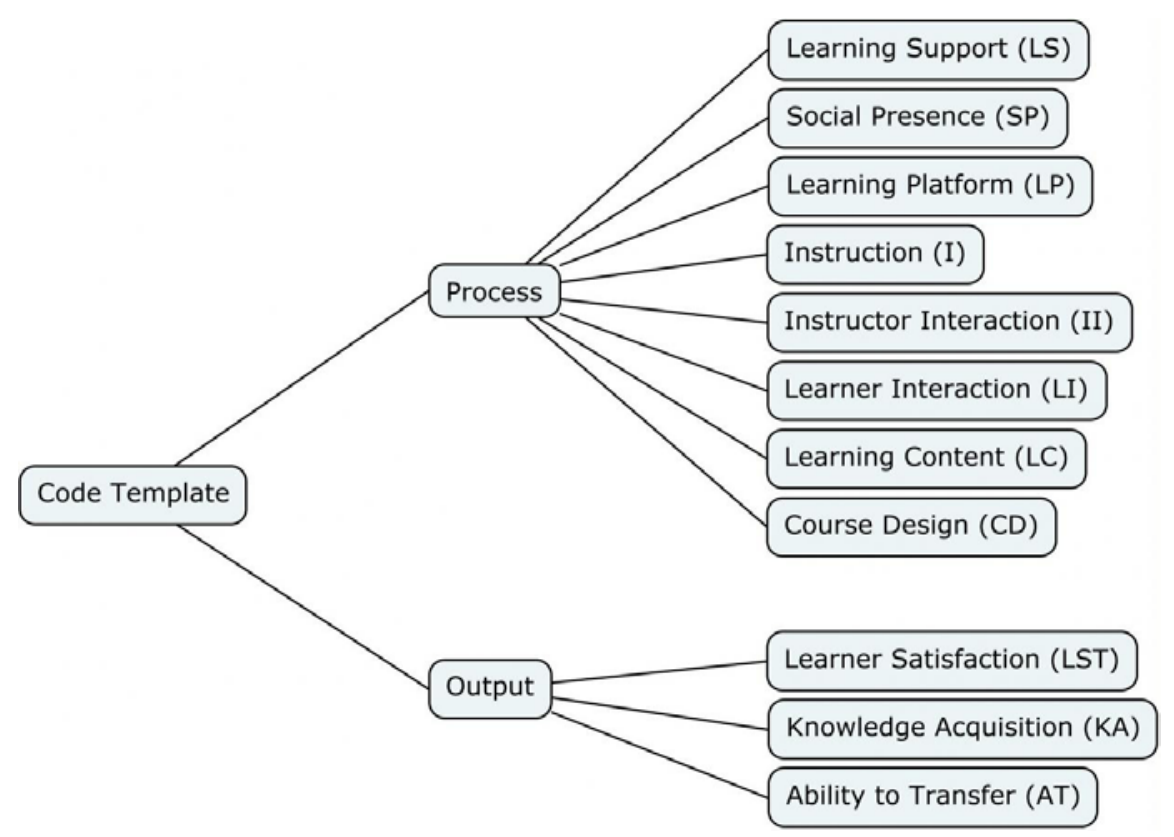

Figure 1. Final code template

Two versions of each code were considered: the first one for positive opinions (+), and the second one for negative opinions (-). After achieving a stable code template, the two researchers coded the text. The first coder acted as the master coder (and coded the whole text), whereas the second coder tested the intercoder reliability. The freely available Weft QDA was used for coding.

\section{Results and discussion}

\section{Defining instructors' roles through factor analysis}

This subsection explores the main roles of the online instructors according to students' perceptions (research question 1). After applying the dropping criteria explained in the Method section, the original 69 items of the questionnaire were reduced to 43 items, which loaded into six factors: pedagogical role, course designer role, social role, life skills promoter role, technical role, and managerial role. These six factors explain $76 \%$ of the variance. The loadings of the items on the six factors are reported in Figure 2. 


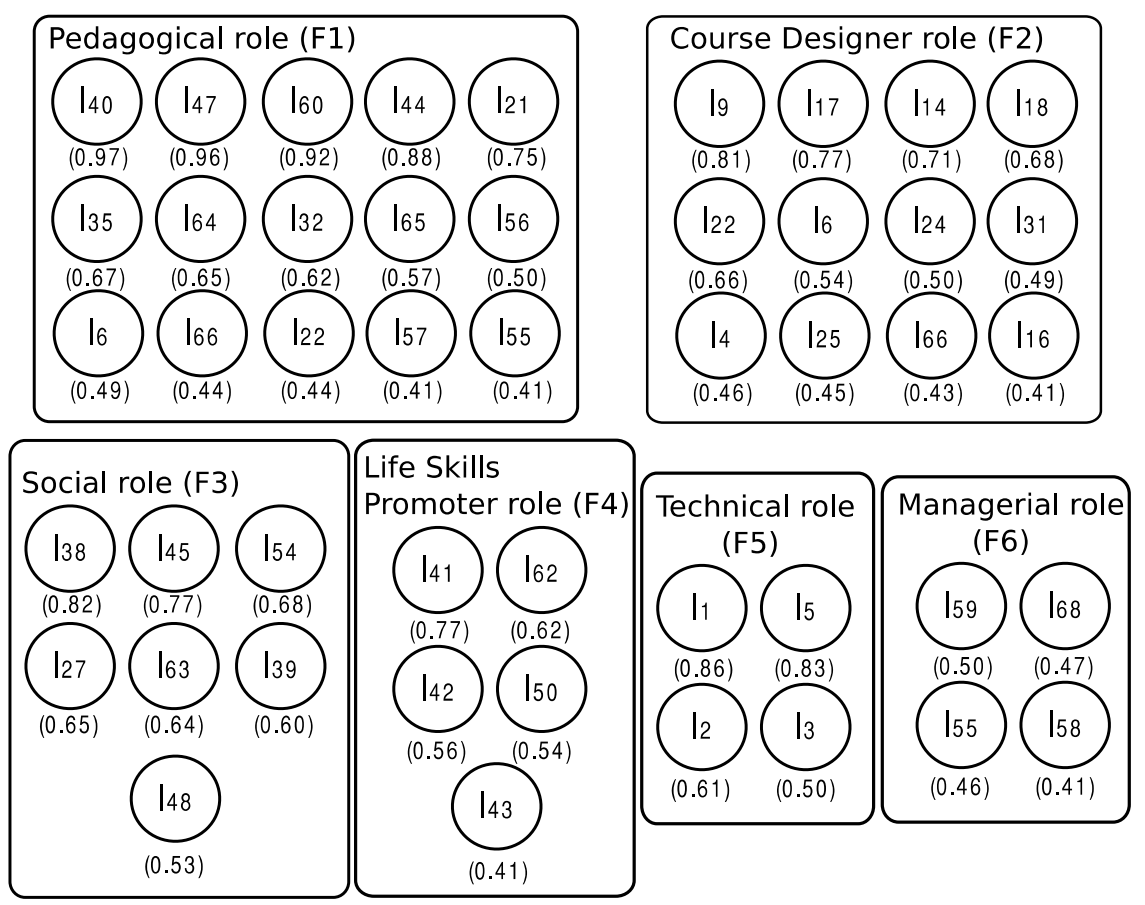

Figure 2. Diagram representing the factor structure of the final 43-item educational role-based model. The pedagogical role includes the $28 \%$ of the total variance, course designer $18 \%$, social $10 \%$, life skills promoter $8 \%$, technical $6 \%$, and managerial $6 \%$.

Factor 1 (pedagogical role) reflects the pedagogical attributes of the instructor. The pedagogical role could be viewed as a main construct that encompasses the following sub-roles: (i) professional, (ii) content expert, and (iii) resource material creator and study guide producer. First, instructors should be good instructors. Second, instructors should be content facilitators with an excellent mastery of their subject matter (Selvi, 2010). Third, it is important to provide an adequate, useful, and comprehensible set of materials (syllabus, educational resources, and content material) at the beginning of the semester (Simonson, Smaldino, Albright, \& Zvacek, 2014).

Factor 2 (course designer role) includes the design of instructional strategies for the learning environment and, therefore, corresponds to the designer role. In the literature, some authors include the designer role as part of the pedagogical one, whereas others divide the tasks encompassing these roles into two different roles (Bawane \& Spector, 2009; Carril, Sanmamed, \& Selles, 2013; Goodyear et al., 2001; Guasch, Alvarez, \& Espasa, 2010). There are some online courses that are designed by experts (instructional designers), but taught by a different person (instructors); while in other online courses, the same person is in charge of both tasks.

Factor 3 refers to the social role. The instructional social role is particularly important in the twenty-first century framework of learning, where communication and teamwork skills are stressed as the key competencies to be developed by today's students (Fisher \& Frey, 2015). Furthermore, this role has special significance in online learning, where there is no physical classroom to promote relationships between students-instructor (group relationship) or student-instructor (individual relationship).

All educators want to help their students succeed in life, even more so at university level, where students are being trained for a specific qualification. This fact is particularly reflected in Factor 4 (life skills promoter role), which refers to the instructors' role as life skills promoters. This role is encouraged by the European Union, the OECD, and UNESCO. Life skills can be defined as personal management and social skills that are necessary for adequate functioning on an independent basis (Delors, 2013).

Factor 5 corresponds to the technical role. This role has been stressed as one of the main pillars of the online instructor's role since the very beginning of research on this topic (Berge, 1995). Online 
instructors should know what digital culture offers, not only technically, but also in the educational domain, and be able to use technology effectively.

Finally, the domain in which the instructor sets the main learning rules, routines, and procedures is represented in Factor 6 (managerial role). This role has been extensively studied in the online learning literature by different authors (Gonzalez-Sanmamed et al., 2014; Liu, Bonk, Magjuka, Lee, \& Su, 2005). The role involves tasks such as setting minimal ethical norms, procedural rules (deadlines) and decisionmaking norms.

A CFA was performed on the two samples to test the 6-factor solution obtained through EFA. The Tucker-Lewis Index and comparative fit index (CFI) were around or above 0.90, which indicates a good fit for the model. Furthermore, the root mean square residual (RMSR) and root mean square error of approximation (RMSEA) were below the usually recommended cut-off values (Hair, Black, Babin, \& Anderson, 2009). Thus, the 6-factor solution represents an acceptable fit based on the usual criteria employed in structural equation modelling.

\section{Statistical analysis of the scores obtained per role}

This subsection aims to determine the teaching effectiveness according to the instructors' roles in online learning (research question 2). The scores per role were estimated by weighting the performance reported by students in each of the questions defining each role by its corresponding factor loading. Unfortunately, each role is defined by a different number of questions. For this reason, the scores of each role were normalised as follows, where $s_{n}^{i}$ is the score obtain ned in the $i$-th role using the feedback of the $n$-th student, $w_{j}^{i}$ is the $j$-th factor loading of the $i$-th role and $x_{n j}^{i}$ is the output reported by the $n$-th student in the $j$-th question of the $i$-th role.

$s_{n}^{i}=\frac{\Sigma_{j} w_{j}^{i} x_{n j}^{i}}{\Sigma_{j} w_{j}^{i}}, n=\{1,2, \ldots, 613\} ; i=\{1,2, \ldots, 6\}$

After obtaining the normalised scores, the outputs of the roles for each student were ranked according to this value ( $R=1$ being the best performing role and $R=6$ the worst one). The mean ranking per role was also computed $(\bar{R})$. In this way, the normalised average score (AE) for each role and the mean of their rankings are calculated and shown in Table 1 . Hence, Table 1 reports the average results across all the students for the roles which are being compared, including the value for the normalised average scores, $\mathrm{AE}$, and the average ranking, $\bar{R}$. From the analysis of the results, it can be concluded, from a purely descriptive point of view, that it is the managerial role that is being best implemented in online environments from the students' perspective $\left(A E_{M}=4.29\right.$ and $\left.\bar{R}_{M}=2.03\right)$, followed (in descending order) by the technical role, pedagogical role, course designer role, social role and, finally, the life skills promoter role $\left(A E_{L S P}=2.76\right.$ and $\left.\bar{R}_{L S P}=5.27\right)$, in the last position.

Table 1

Statistical results for instructor performance obtained in each role

\begin{tabular}{lll}
\hline \multicolumn{3}{c}{ Normalised Score } \\
\hline & Average score (AE) & $R$ \\
\hline Pedagogical (P) & 4.07 & 2.61 \\
Course designer (CD) & 3.52 & 4.02 \\
Social (S) & 3.04 & 4.67 \\
Life skills promoter (LSP) & 2.76 & 5.27 \\
Technical (T) & $4.11^{* *}$ & $2.41^{* *}$ \\
Managerial (M) & $4.29 *$ & $2.03^{*}$ \\
\hline Note. * best result, ** second best result
\end{tabular}

The significance of the experimental results was assessed using non-parametric statistical tests, since a previous evaluation of the average scores obtained in the instructors' roles resulted in rejecting the 
normality and the equality of variances hypothesis. Specifically, we have used the Friedman and Nemenyi statistical tests. The Friedman test checks if there are significant differences in the group of results, while the Nemenyi test is used to detect which of all the comparable pairs have significant differences (Zar, 1999). The pre-hoc Friedman test was performed with the average ranking obtained in each role. The test showed that there were statistical differences between the scores obtained in the different roles at a significance level of $5 \%$, as the confidence interval is $C_{0}=\left(0 ; F_{0.05}=2.22\right)$ and the F-distribution statistical values are $F^{*}=633.69 \notin C_{0}$. Therefore, the null-hypothesis is rejected stating that all roles are performed equally in mean ranking.

Based on the previous rejection results, the Nemenyi post-hoc test was used in order to compare all the roles with each other. The Nemenyi test analyses the performance of different roles considering that a role is significantly different if its mean rank differs by at least the critical difference (CD). The results of the Nemenyi test for $\alpha=0.05$ can be seen in Figure 3, where the CD is also shown, and the mean ranking of each role is represented on the scale. When the mean rankings of two algorithms differ more than the $\mathrm{CD}$, then significant differences can be assessed.

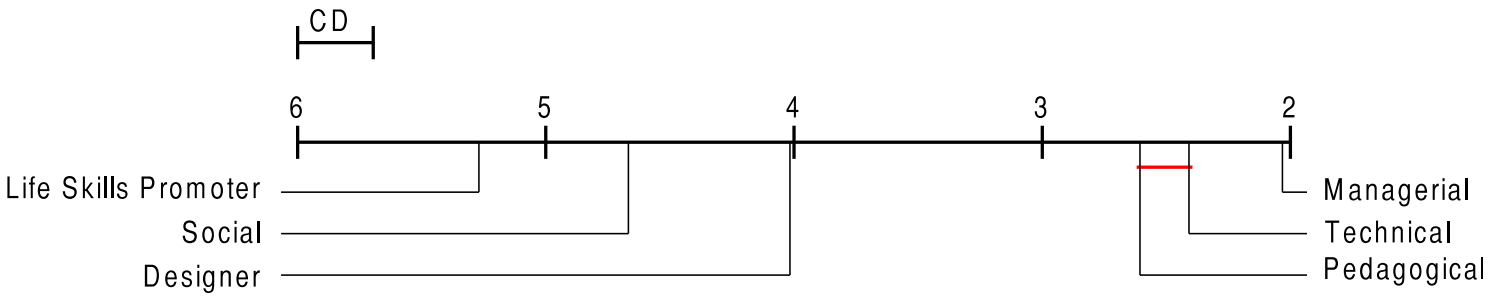

Figure 3. Ranking test diagram for the mean ranking scores obtained per role $(\alpha=0.05)$

The results of the Nemenyi test for $\alpha=0.05$ show that the managerial role is significantly better implemented in online environments than the remaining ones. Note that there are no significant differences at the level of implementation in the course between the technical and pedagogical roles. However, these roles are significantly better implemented than the designer role and those roles with worse ranking than this one. Finally, it is important to note that the social role is significantly better implemented than the life skills promoter role, but implemented significantly worse than the designer one.

Teaching effectiveness was also assessed by analysing the students' comments in the last question of the questionnaire. As previously mentioned, template analysis was implemented to perform the corresponding analysis on those qualitative data. Figure 4 shows the frequencies for each code, using the master coding. Those frequencies will be analysed in the next section. In our opinion, this codification represents the phenomenon being analysed as all inter-coder reliability coefficients associated with each code, were deemed acceptable according to established standards in template analysis. 


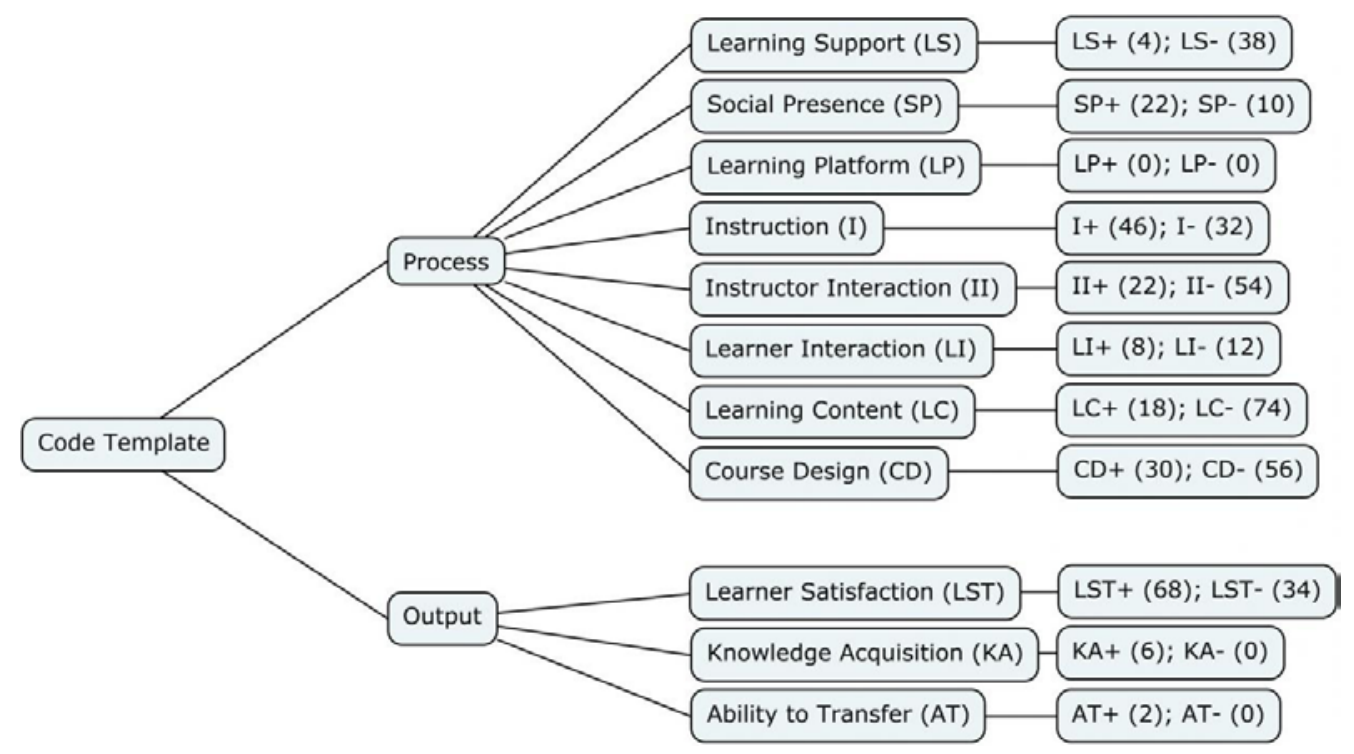

Figure 4. Frequency codes of the qualitative data

\section{Interpretation of results}

The goal of this subsection is to interpret the results obtained in previous subsections in educational terms. Statistical results obtained from the Likert scale questions will be complemented with the qualitative data obtained in the last open-ended question of the questionnaire. In the study, the managerial role was rated as the best implemented one at UOC from the students' point of view. This is a positive finding, as several studies from the literature claim that effective classroom management is probably one of the most important responsibilities assumed by educators (Emmer \& Stough, 2001; Stewart, 2008). We hypothesise that the syllabus students receive at the beginning of the semester is the main reason for the high ranking reported in the managerial role. Instructional designers place special emphasis on the design of this descriptive document, which gives students not only educational information (the main objectives of the course), but also all details forms of normalisation (for instance, ethical norms, procedural rules, and decision-making norms) that make the learning environment more transparent and intuitive. Furthermore, thanks to the clear syllabus design, the tasks in the managerial role occupied a smaller proportion of the teachers' working time, leaving more time for other learning tasks.

As described in the previous subsection, the technical and pedagogical roles held second position in the overall ranking of instructors' roles. Although from the student point of view there were no significant differences between these roles in the implementation, the former obtained an average score of 4.07 whereas the latter received 4.11. We hypothesise that the learning management system (LMS) used by the university being studied, has significantly helped the technical role to rank so highly with respect to the remaining roles. The LMS implemented at the UOC allows instructors to offer learning tracking (e.g., learning interaction), reporting (e.g., syllabus and material), and delivery (e.g., continuous assessment) anywhere and anytime. Furthermore, the UOC has known how to incorporate changes occurring in the new digital society into its LMS. For example, the current LMS already includes functionalities such as a Wordpress blog and a Wikispace with the aim of providing a more collaborative online learning space that helps instructors to improve their implementations of the social and life skills roles (Garreta Domingo, \& Santanach, 2010).

However, the technical role also involves resolving technical issues (Goodyear et al., 2001). Apparently, online instructors were already aware of this aspect, as they were not only rated very highly on this point (65.08\% of students rate question 1 , with 4 or 5 points), but they also received positive feedback in a question where students could freely express their views on the faculty and teaching process. Below is an example of this positive feedback provided by a student with respect to the technical role of the instructor: "I am astonished at how in an online environment instructors are able to solve technical incidents in such a short period of time. Unbelievable!” (Participant 321). 
Students valued the pedagogical attributes of an instructor as very well implemented (with an average score of 4.07/5). As claimed by Berge (1995), the pedagogical role is one of the most important roles of the online moderator/tutor. Analysing the students' comments, we realised that this was mainly due to two facts: (i) instructors promoted the development of effective communication skills among their students and showed a favourable attitude in their interactions with students; and (ii) instructors were content facilitators with an excellent mastery of their subject matter (I+ code frequency = 46; I- code frequency= 32; LST+ code frequency $=68$; LST- code frequency $=34$ ). Some comments, reflected these pedagogical issues: "I am very pleased with my instructor. He was very friendly and treated the students politely. He always clarified my doubts in an effective and efficient way" (Participant 273); and "I am very grateful to my instructor for facilitating students' work and making us understand the theory much better with his explanation on the forum” (Participant 25).

Moreover, instructors provided an adequate set of materials (syllabus, educational resources, and content material) at the beginning of the semester, thus allowing students to read and prepare the subject in advance. The designer role achieved a competitive normalised score of 3.52 out of 5 . As described by Romiszowski (2016), this role is critical to the success of the learning experience and so we will describe some possible areas of improvement. These results were obtained by analysing students' feedback, which highlighted that learners believe instructors could better stimulate the learning experience by using reallife situations/examples in their explanation/materials, thereby enhancing their engagement, retention and success $(\mathrm{LC}+$ code frequency $=18$; $\mathrm{LC}$ - code frequency $=74)$. This fact is reflected in the following student comment: "As a constructive criticism, I think that the material should be more enjoyable, showing more real-life examples to better understand and follow the subject” (Participant 496).

Furthermore, although $70.30 \%$ of students were in general very satisfied with the course material provided (rating question 22, with 4 or 5 points), there was almost a consensus in the students' ideas for improvement. Firstly, they asked for readable, pleasant and organised material. Secondly, they found the material onerous or burdensome. They would have liked the materials to be concise, succinct and relevant. These perceptions are evidenced in the following comments: "The course material was complicated and confusing. From my point of view, there were some definitions that could be made much clearer and more understandable" (Participant 405); and "The subject content is so onerous and burdensome" (Participant 504).

In addition to these issues, online environments require a course design that takes the students' needs into account, as adult learners usually have other commitments $(86.10 \%$ of our sample had work or family commitments). Although there was generally positive feedback on this issue, $18.27 \%$ of students described some areas for improvement (evaluating their instructor with only one or two points on question 29) $(C D+$ code frequency $=30$; $C D$ - code frequency = 56). Some of the students' perceptions on this point were: "I am a little bit disappointed with the lack of flexibility during my learning experience. Although I am a mother and I work, I want to study. I enrolled in this university because I thought that the online system of this university was more flexible. However, I had a tough experience" (Participant 608); "I think you need to make a great effort to combine the studies from this university with work and/or other personal obligations required” (Participant 313).

The social role has been reported to be one of the key online instructors' roles since the beginning of research into online instructors' roles (Berge, 1995). In this study, this role was one of the most poorly implemented roles according to the students' perceptions. Despite this, this role obtained an average score of 3.04 out of 5 . This could be due to the fact that online students have traditionally spent most of their educational stages (from school to university) in a synchronous traditional environment and may not yet be used to studying in online environments (LS+ code frequency $=4$; LS- code frequency $=38$ ). The lack of training in these contexts is mentioned in the following comment: "I missed some kind of synchronous communication with my instructor, for instance, a few hours a week of chat or video conference in order to expedite the resolution of doubts and problems” (Participant 248).

Along these lines, we are seeing a significant increase in the number of students who are frustrated with dry, textbook studying, and need more effective and audio-visual resources, such as videos and interactive material ( $\mathrm{LC}+$ code frequency $=18$; $\mathrm{LC}$ - code frequency $=74$ ). This fact is illustrated in the students' comments: “Online learning is complex and, therefore, in addition to the material and bibliography that we received at the beginning of the course, it would be nice to have audiovisual 
material" (Participant 421); and "I would like to suggest the inclusion of videos recorded by our instructors. Furthermore, taking into account the little amount of time that students from this environment have, it would be more enjoyable to watch a video than reading onerous material” (Participant 346). In fact, there were some instructors who used videos in their subjects, and students valued this initiative positively, encouraging their instructors to continue using them as reported in the suggestion box question. A learner comment confirmed this evidence by reflecting positive feelings towards the use of videos: "My instructor sent students a few videos that were extremely useful for my learning process. In fact, I would have liked more of them” (Participant 176).

Finally, it is worth mentioning that students ranked the life skills promoter role in the last position (with an average score of 2.76/5). The implementation of this role requires the development of transversal skills such as teaching values, for instance, empathy, tolerance and being respectful to other cultures, and beliefs. These soft skills are mandatory in the twenty-first century, as suggested by UNESCO (Delors, 2013) and recent research studies (Gómez-Rey et al., 2016a). The university is aware of this and, for that reason, the course design includes both individual activities in the students' learning experience and also collaborative tasks where these kinds of values are easier to promote. Intuitively, face-to-face learning has significant advantages when fostering the development of these values, thanks to the permanent human contact between peers. Unfortunately, the development and promotion of such values is much more difficult in online environments, as shown in the following students' comments: "Working in a team in an online environment with peers who I do not know and who do not share my interests, leads to failure. Sooner or later, conflicts between team mates arise and no one is satisfied with the work done" (Participant 269); "In my opinion, the university should remove the group assignments because it is very distant to work with peers who are not physically in the same place. Furthermore, it is very difficult to cope with my daily life. For instance, I work in a hotel, most of the time with a night schedule and, therefore, it is impossible to coordinate myself with my classmates these days" (Participant 104). As can be seen, collaborative activities are negatively assessed for online learners (LI+ code frequency = 8; LIcode frequency $=12$ ) who seek flexibility in their studies and perceive group learning as an impediment to their progress (Brindley, Blaschke, \& Walti, 2009). Despite this, the benefits for students in developing this type of activity are highlighted by Gay (2016).

This study has provided a snapshot of online instructors' roles and teaching effectiveness in online learning, although the findings should be viewed with some caution. Firstly, the findings of the study were obtained from an open university sample with an educational model based on text-based learning and asynchronous communication between the main actors (students and instructors), and therefore, the results may be specific to this type of environment. Conclusions drawn from the study may be used to improve teaching and learning practices in similar learning contexts. A second limitation of the study is the low response rate obtained, which increase the likelihood of a non-response bias in play (people of a particular ilk are systematically not represented in the sample). Despite this, we obtained a sample with more than 900 students from different degrees and ages, which in our opinion, is representative of the population under study.

\section{Implications for policy and practice}

The findings of this study have direct implications for educational policy-makers, instructional designers, and educators. Educational policy-makers could develop a new aggregate index of online teaching effectiveness based on the roles identified in the study. This measure could be used to assess the level of teaching effectiveness in universities with the same educational approach (i.e., text-based learning and asynchronous communication). Furthermore, this potential educational index could be also used to generate a discussion about what policies contribute to improve teaching effectiveness.

Instructional designers could take advantage of students' feedback and adapt the material offered to their needs, including not only real-life examples, but also readable, pleasant, relevant and concise course material. Furthermore, this research revealed the need to develop synchronous communication channels in the context of text-based communication. In a similar way, educators could also use the findings of the study to adapt their teaching strategies and focus their efforts on those peripheral roles with the most impact for the students' community, also analysing the level of implementation of each role. 


\section{Conclusion}

The goal of the study was twofold: (1) to identify existing online instructors' roles; and (2) to evaluate teaching effectiveness in online learning according to the performance of the instructors in their roles and duties. Regarding research question 1, the methodological approach adopted in the study detected the emergence of a new role, the life skills promoter, which should be added to the already known set of online instructors' roles. Numerous organisations (e.g., European Union, OECD, and UNESCO) are promoting life skills-based education to prepare individuals of the twenty-first century to succeed in life. However, previous research works on the topic do not include in their educational models, roles that are devoted to students' development of the core set of skills which are required to succeed in today's society. Although the topic of the role of online instructors has been extensively researched over the past two decades, it is interesting to see how these roles change with society's needs. Regarding research question 2, the managerial role is the best implemented role at UOC from students' point of view, followed by the technical role, the pedagogical role, the designer role, the social role, and the life skills promoter role. In this context, three main findings were identified: (1) online scenarios are becoming more transparent and intuitive due to syllabus design; (ii) instructors from asynchronous learning environments should consider using more audio-visual resources in their virtual classrooms; and (iii) students should be offered concise and practical guidelines for collaborative activities to reduce the level of frustration with these activities. Additionally, the results of the study are also aligned with those of the literature, in the sense that, the pedagogical role acts as a central role whereas the remaining ones behave as peripheral ones (González-Sanmamed et al., 2014). It is important to mention that the study was designed using a sample obtained from an asynchronous learning university, and therefore the results may be specific to this kind of environment.

Future research will focus on operationalising and monitoring the life skills promoter role. Education in the twenty-first century is characterised by a globalised world that requires students not only to be achievers at university, but also responsible citizens, effective workers, and caring and culturally sensitive community members. In this context, a preliminary theoretical study has already been presented by Gómez-Rey, Barbera, \& Fernández-Navarro (2015). This previous work described a potential operationalisation of the capability approach (CA) for the online learning community, which in our opinion covers today's educational needs. Furthermore, future works can take advantage of this framework by creating an evaluation instrument to evaluate the strengths and weaknesses of an online university in the application of life-long education.

\section{Acknowledgements}

The research work of Pilar Gómez-Rey has been supported with a doctoral grant from the Universitat Oberta de Catalunya. The authors are grateful to the instructors and learners of the university for participating in this study.

\section{References}

Abdulla, A. G. (2004). Distance learning students' perceptions of the online instructor roles and competencies (Doctoral dissertation). Florida State University, FL Retrieved from http://www.citeulike.org/user/jrhode/article/1029039

Bawane, J., \& Spector, J. M. (2009). Prioritization of online instructor roles: Implications for competency-based teacher education programs. Distance Education, 30(3), 383-397. https://doi.org/10.1080/01587910903236536

Berge, Z. L. (1995). The role of the online instructor/facilitator. Educational Technology, 35(1), 22-30.

Berk, R., (2005). Survey of 12 strategies to measure teaching effectiveness. International journal of teaching and learning in higher education, 17(1), 48-62. Retrieved from https://www.apgo.org/binary/2012\%2012c\%20Survey\%20of\%2012\%20Strategies\%20to\%20Measure \%20Teaching\%20Effectiveness.pdf

Bezuidenhout, A. (2015). Implications for academic workload of the changing role of distance educators. Distance Education, 36(2), 246-262. https://doi.org/10.1080/01587919.2015.1055055 
Brindley, J., Blaschke, L. M., \& Walti, C. (2009). Creating effective collaborative learning groups in an online environment. The International Review of Research in open and distributed Learning, 10(3), 118. https://doi.org/10.19173/irrodl.v10i3.675

Brooks, J., McCluskey, S., Turley, E., \& King, N. (2015). The utility of template analysis in qualitative psychology research. Qualitative Research in Psychology, 12(2), 202-222. https://doi.org/10.1080/14780887.2014.955224

Carril, P. C. M., Sanmamed, M. G., \& Selles, N. H. (2013). Pedagogical roles and competencies of university teachers practicing in the e-learning environment. The International Review of Research in Open and Distributed Learning, 14(3), 462-487. https://doi.org/10.19173/irrodl.v14i3.1477

Delors, J., 2013. The treasure within: Learning to know, learning to do, learning to live together and learning to be. What is the value of that treasure 15 years after its publication? International Review of Education, 59(3), 319-330. https://doi.org/10.1007/s11159-013-9350-8

Emmer, E. T., \& Stough, L. M. (2001). Classroom management: A critical part of educational psychology, with implications for teacher education. Educational psychologist, 36(2), 103-112. https://doi.org/10.1207/S15326985EP3602_5

Fisher, D., \& Frey, N. (2015). Engaging the adolescent learner: Setting the stage for 21st-century learning. Newark, DE: International Literacy Association.

Fox, M. A., \& Hackerman, N. (2003). Evaluating and improving undergraduate teaching in science, technology, engineering, and mathematics. Washington, WA: National Academy Press.

Garreta Domingo, M., \& Santanach, F. (2010, July). Open to the users' needs: combining user-centered design, standards and open source software. Paper presented at the Open ED 2010 Conference, Barcelona.

Gay, G. H. (2016). An assessment of online instructor e-learning readiness before, during, and after course delivery. Journal of Computing in Higher Education, 28(2), 199-220. https://doi.org/10.1007/s12528-016-9115-z

Gómez-Rey, P., Barbera, E., \& Fernández-Navarro, F. (2015). Operationalization of the Capability Approach for online learning. Proceedings of the 8th International Conference of Education, Research and Innovation (pp. 8200-8207). Seville: IATED.

Gómez-Rey, P., Barbera, E., \& Fernández-Navarro, F. (2016a). The impact of cultural dimensions on online learning. Journal of Educational Technology \& Society, 19(4), 225-238. Retrieved from http://www.ifets.info/journals/19 4/19.pdf

Gómez-Rey, P., Barbera, E., \& Fernández-Navarro, F. (2016b). Measuring teachers and learners' perceptions of the quality of their online learning experience. Distance Education, 37(2), 146-163. https://doi.org/10.1080/01587919.2016.1184396

Goodyear, P., Salmon, G., Spector, J. M., Steeples, C., \& Tickner, S. (2001). Competences for online teaching: A special report. Educational Technology Research and Development, 49(1), 65-72. https://doi.org/10.1007/BF02504508

Goold, A., Coldwell, J., \& Craig, A. (2010). An examination of the role of the e-tutor. Australasian Journal of Educational Technology, 26(5), 704-716. https://doi.org/10.14742/ajet.1060

González-Sanmamed, M., Muñoz-Carril, P. C., \& Sangra, A. (2014). Level of proficiency and professional development needs in peripheral online teaching roles. The International Review of Research in Open and Distributed Learning, 15(6), 162-187. https://doi.org/10.19173/irrodl.v15i6.1771

Gorsky, P., \& Blau, I. (2009). Online teaching effectiveness: A tale of two instructors. The International Review of Research in Open and Distributed Learning, 10(3), 1-27. https://doi.org/10.19173/irrodl.v10i3.712

Guasch, T., Alvarez, I., \& Espasa, A. (2010). University teacher competencies in a virtual teaching/learning environment: Analysis of a teacher training experience. Teaching and Teacher Education, 26(2), 199-206. https://doi.org/10.1016/j.tate.2009.02.018

Hair, J. F, Black, W. C., Babin, B. J., \& Anderson, R. E. (2009). Multivariate data analysis. Westlake Village, CA: PrenticeHall.

Liu, X., Bonk, C. J., Magjuka, R. J., Lee, S. H., \& Su, B. (2005). Exploring four dimensions of online instructor roles: A program level case study. Journal of Asynchronous Learning Networks, 9(4), 2948. Retrieved from http://onlinelearningconsortium.org/jaln_article/exploring-four-dimensions-ofonline-instructor-roles-a-program-level-case-study-2/

Marsh, H. W. (1984). Students' evaluations of university teaching: Dimensionality, reliability, validity, potential biases, and utility. Journal of Educational Psychology, 76(5), 707-754.

https://doi.org/10.1037/0022-0663.76.5.707 
McCrae, R. R., \& Terracciano, A. (2005). Universal features of personality traits from the observer's perspective: data from 50 cultures. Journal of personality and social psychology, 88(3), 547. https://doi.org/10.1037/0022-3514.88.3.547

McKeachie, W. J. (1979). Student ratings of faculty: A reprise. Academe, 65(6), 384-397. https://doi.org/10.2307/40248725

Pellegrino, J. W., \& Hilton, M. L. (2013). Education for life and work: Developing transferable knowledge and skills in the 21st century. Washington, DC: National Academies Press.

Romiszowski, A. J. (2016). Designing instructional systems: Decision making in course planning and curriculum design. New York, NY: Routledge.

Schweisfurth, M. (2015). Learner-centred pedagogy: Towards a post-2015 agenda for teaching and learning. International Journal of Educational Development, 40, 259-266. https://doi.org/10.1016/j.ijedudev.2014.10.011

Sekaran, U., \& Bougie, R. (2010). Theoretical framework and hypothesis development. In U. Sekaran, \& R. Bougie (Eds.). Research methods for business: A skill building approach (pp. 67- 100). United Kingdom: Wiley.

Selvi, K. (2010). Teachers' competencies. Cultura: International Journal of Philosophy of Culture and Axiology, 7(1), 167-175. https://doi.org/10.5840/cultura20107133

Shaikh, Z. A., \& Khoja, S. A. (2014). Personal learning environments and university teacher roles explored using Delphi. Australasian Journal of Educational Technology, 30(2), 202-226. https://doi.org/10.14742/ajet.324

Simonson, M., Smaldino, S., Albright, M. J., \& Zvacek, S. (2014). Teaching and learning at a distance. Charlotte, NC: Information Age Publishing.

Stewart, D. (2008). Classroom management in the online environment. Journal of online learning and teaching, 4(3), 371-374. Retrieved from http://jolt.merlot.org/vol4no3/stewart 0908.pdf

Thach, E. C., Murphy, K. L. (1995). Competencies for distance education professionals. Educational Technology Research and Development, 43(1), 57-79. https://doi.org/10.1007/BF02300482

Zar, J. H. (1999). Biostatistical analysis. Upper Saddle River, NJ: Prentice Hall City.

Corresponding author: Pilar Gómez-Rey, pgomez_del_rey@uoc.edu

Australasian Journal of Educational Technology (c) 2018.

Please cite as: Gómez-Rey, P., Barbera, E., \& Fernández-Navarro, F. (2018). Students' perceptions about online teaching effectiveness: A bottom-up approach for identifying online instructors' roles. Australasian Journal of Educational Technology, 34(1), 116-130. https://doi.org/10.14742/ajet.3437 


\section{Appendix A \\ Desired items for online instructors' outputs}

\section{Non-demographics questions}

1. My professor has the skills to help (possesses basic understanding of technology) if I had a technical question.

2. My professor knew the correct technical expert to contact if I had a technical question that went beyond his/her technical skills.

3. My professor has acted as a liaison with technical/support staff if I had a technical question/problem.

4. My professor provided me with valuable materials (demos or manuals) addressing the most common technical issues.

5. My professor gave me swift feedback when I experienced a technical problem.

6. My professor used useful educational resources to help students learn the content.

7. My professor provided me with adequate time to be comfortable with the technology before active participation was required.

8. My professor asked the students about the effectiveness and efficacy of the technology used in the semester.

9. I did debates/discussion activities in this subject.

10. I did polling activities in which it has required students' opinion (dates, type of activity ...) in this subject.

11. I did individual activities in this subject.

12. I did written activities in this subject.

13. I did oral activities in this subject.

14. My professor proposed activities where students had "fun" while learning (for example: educational games, analyse videos/movies).

15. I did activities in which there was only one right answer in this subject.

16. I did activities in which there was more than one right answer.

17. My professor provided me with material/activities where I had to make an effort to understand other cultures and life perspectives.

18. My professor has proposed questions/activities that took into account students' experiences.

19. My professor gave students the opportunity of doing activities in a group (two or more students) taking into account the students' common interest in the content or educational intellectual capabilities.

20. In activities that required interaction (for instance: debates), my professor summarized the content (every certain period of time) in order to prompt students to pursue the topic further.

21. My professor participated in activities with the students (making suggestions, giving advice, sending reminders).

22. My professor provided me with valuable materials (demos, manuals, website).

23. My professor reminded me about the importance of justifying or referencing open answer activities with data or scientific works.

24. My professor informed me of events I could attend (lectures, conferences) or recommended an expert in the subject (recommended his/her bibliography), to help me learn the content of the subject.

25. My professor showed concern about students, e.g., by asking specific students to comment on a topic or question and giving them enough time.

26. My professor encouraged me to interact with my peers to help in learning the content.

27. My professor gave me feedback on an activity that I submitted after the deadline (even if he/she did not take into consideration this activity in my evaluation).

28. My professor maintained a non-authoritarian style.

29. My professor designed the course taking into account that I have other commitments (work, family or leisure time).

30. My professor was concerned about my interests at the beginning of the course.

31. My professor used open-ended remarks and examples during the course.

32. My professor assessed me fairly and accurately according to the criteria established in the evaluation guidelines of the course.

33. My professor encouraged me to participate in discussion activities/forum helping me to not have the fear of ridicule because of my grammar or typing.

34. My professor publicly praised good behaviour (e.g., by praising to students who respond effectively to the online activities).

35. During the semester, my professor has advised and counselled me (i.e., motivational comments, technical techniques, online strategies).

36. My professor welcome latecomers, e.g., the professor said: "There are no comments from some of you. 
Please, feel free to participate as your opinions are more than welcome”).

37. My professor encouraged students to introduce themselves.

38. My professor sent me a message (privately) when I appeared overly outspoken/frank in stating my opinions, especially if they were shocking or controversial.

39. My professor warned me not to overload the discussion activities with worthless contributions.

40. My professor was easily accessible.

41. My professor encouraged me to use the English language (e.g., by asking a question or doing an activity in English).

42. My professor's sense of humour was culturally sensitive to other life perspectives or ethnicities.

43. My professor provided me with respectful communication guidelines for avoiding the use of harsh or vulgar language.

44. My professor showed an open, enthusiastic and personable attitude during the semester.

45. My professor sent me a message (privately) when I was absent (e.g., when I did not participate in the class forum, I did not submit an activity or I had poor behaviour during discussions).

46. My professor (or the institution) made available a list of students (names and emails) that were enrolled in the course.

47. My professor provided me with timely feedback to my requests.

48. My professor provided me with information about such things as registration, admissions, student counselling and other administrative activities.

49. My professor assisted me in my library searches/research about extra course material.

50. My professor provided me with information about institutional activities such as academic events, workshops or news related to the institution.

51. My professor did not overwhelm me with lots of messages when I did not participate in the forum class or activities.

52. My professor invited participants to give feedback about how they feel about the course (what things they like/dislike, what things they would like to change and how).

53. My professor ensured that all students began in unison and in an organized fashion.

54. My professor acted as a mediator in contentious discussions among students.

55. At the beginning of the course, my professor provided me with valuable materials (demos or manuals) containing information about the course components (objectives, evaluation criteria and learning strategies).

56. During the course, my professor reminded me about the course components (objectives, evaluation criteria and learning strategies).

57. My professor provided course materials at the beginning of the course or activity, thus helping his/her students to complete assignments on time.

58. My professor closes the sessions/discussions/activities after they have fulfilled their initial purposes.

59. My professor advised that plagiarism is penalized.

60. My professor communicated any information in a clear, understandable and organized manner.

61. My professor has a mother tongue proficiency (e.g. Spanish or Catalan).

62. My professor provided students with English materials (e.g., references).

63. My professor has foreign language proficiency (English, in general).

64. My professor has extensive knowledge for teaching the subject.

65. My professor has demonstrated himself/herself to be up-to-date about the content of this subject.

66. My professor provided me with materials that are clear, understandable and very well organized.

67. My professor asked me how the course materials could be changed in order to be more attractive, clear and facilitate learning.

68. My professor emphasized the importance of task deadlines.

69. At the beginning of each unit, my professor gave an orientation planning that helped me to plan my study.

- Any other comment about your learning experience? 